\title{
Subfossil European bog oaks: population dynamics and long-term growth depressions as indicators of changes in the Holocene hydro-regime and climate
}

\author{
Hanns Hubert Leuschner, ${ }^{1 *}$ Ute Sass-Klaassen, ${ }^{2}$ Esther Jansma, ${ }^{2,3}$ \\ Michael G.L. Baillie ${ }^{4}$ and Marco Spurk ${ }^{5}$
}

$\left({ }^{1}\right.$ Laboratory for Dendrochronology and Dendroclimatology, University of Göttingen, Von Siebold str. 3a, D-37075 Göttingen, Germany; ${ }^{2}$ The Netherlands Centre for Dendrochronology RING, Kerkstraat 1, NL-3811 CV, Amersfoort, The Netherlands; ${ }^{3}$ National Service for the Preservation of the Archaeological Heritage (ROB), Kerkstraat 1, NL-3811 CV Amersfoort, The Netherlands; ${ }^{4}$ Palaeoecology Centre, Queens University Belfast, Belfast BT7 1NN, Northern Ireland; ${ }^{5}$ Institute of Botany, University of Hohenheim, D-70593 Stuttgart, Germany)

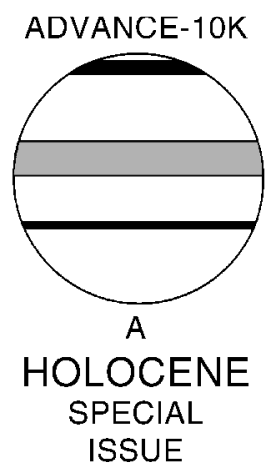

\begin{abstract}
Some 2600 bog oaks have been dated from German, Dutch and Irish bogs covering the period 6000 $\mathrm{BC}$ to $\mathrm{AD} 1000$. The ring patterns of these 'bog oaks' are characterized by recurrent, long-term growth depressions. In addition, obvious changes in the temporal distribution of the bog-oak trunks throughout the Holocene are found. Both features were probably caused by unfavourable growth conditions, which are most likely linked to changes in site hydrology. We use a new variable, 'annual mean age', as a tool to analyse the population dynamics of bog oaks in more detail, enabling the detection of synchronous intersite and interregional changes. It is calculated as the arithmetic mean of the age of all trees in each calendar year. We performed the calculation on regional (Germany, The Netherlands, Ireland) subsets of the bog-oak series. Abrupt changes in annual mean age are taken to indicate periods of generation change. We find good agreement for the interval from 5000 BC to 2000 BC between the continental (combined German and Dutch) and the Irish mean-age chronologies. Most changes in population dynamics correspond with contemporary changes in the associated regional tree-ring chronologies. It is concluded that the observed changes in population dynamics and growth activity are responses to common environmental forcing, most likely related to climate.
\end{abstract}

Key words: Bog oaks, Quercus spp., dendroclimatology, annual mean age, population dynamics, germination, dying-off, Germany, The Netherlands, Ireland, European climate, Holocene.

\section{Introduction}

The dendrochronological data set of absolutely dated subfossil oak trunks from German, Dutch and Irish bogs consists of some 2600 tree-ring series, derived from approximately 200 sites. Until now, research on these 'bog oaks' has provided absolutely dated treering chronologies that extend from $6069 \mathrm{BC}$ to the tenth century AD (Pilcher et al., 1984; Leuschner, 1992; Baillie, 1995; Jansma, 1995; Spurk et al., 1998; Leuschner et al., 2000). The large amount of bog-oak material that has been assembled and placed on an absolute annual timescale offers the possibility to use

*Author for correspondence (e-mail: hleusch@popper.gwdg.de) different means to analyse the time series in terms of hydrology and climate.

The tree-ring patterns of bog oaks from the same sites, as well as from different sites, show common variability, including synchronous intervals of prolonged growth depression (e.g., Baillie, 1995). Studies on population dynamics of German bog oaks show evidence of synchronous intersite germination and dying-off phases, which sometimes coincide with the long-lasting growth depressions (Leuschner et al., 1985; Leuschner, 1992). However, as the number of investigated sites increased the picture became diffuse. It became obvious that, besides regional climatic factors, other, often local, environmental factors were involved (Delorme et al., 1981). The same holds true for the depression phases in the 
tree-ring series. These often appeared simultaneously in trees of one site while lacking in those of other, sometimes even neighbouring, sites. In order to attempt a better understanding of the two phenomena, we made comparisons on a larger geographical scale, between the whole of the German, Dutch and Irish data sets.

The objective of the study is to analyse the population dynamics of bog oaks from different European regions throughout the Holocene. For this purpose we introduced a new parameter, namely the mean age of all oaks in every calendar year. Together with the analysis of common long-term depressions in the regional bog-oak chronologies, we propose a tool to detect overall changes in hydrological site conditions.

\section{The bog-oak material}

Bog oaks occur occasionally in the buried remains of former mire woodlands, where they grew in association with common species of swamp forests such as black alder (Alnus glutinosa), birch (Betula pubescens), willow (Salix spp.) and ash (Fraxinus exelsior). In special cases, oaks have been known to reach ages up to 840 years (Huber et al., 1949); in undisturbed stands, ages of 400 to 500 years are considered normal. However, it is evident that most bog oaks die at much younger ages. This must have been caused by changes in the ecological site conditions and/or stormy phases. The geology, soil structure and hydrology of bog sites are complex and heterogeneous (Overbeck, 1975; Succow and Joosten, 2001). The oaks grew under marginal ecological conditions where high groundwater levels prevailed, either on the margins of peat bogs on mineral soil or - during drier periods directly on the peat. Changes of the hydrology had a major impact on the growth of the trees and the population dynamics of these ancient woodlands. When the groundwater table rose and reached the surface during longer periods of the year, the trees suffered or died due to the shortage of oxygen in the root zone. At the same time the establishment of oaks was inhibited (Kozlowski, 1984; Armstrong et al., 1994).; The horizontal and vertical extension of the bogs caused the trees to become (slowly) overgrown and preserved by the peat (Leuschner and Delorme, 1986). A change to generally drier conditions (decreasing groundwater levels) would eventually lead to the re-establishment of trees at the lower locations of the site.

We used the dated tree-ring series of some 2600 bog oaks from approximately 197 sites located in northern Germany, The Netherlands and Ireland (Figure 1). The results presented here concern the larger part of the European bog-oak data set, though not its totality. The bog oaks from East Anglia have been excluded, as

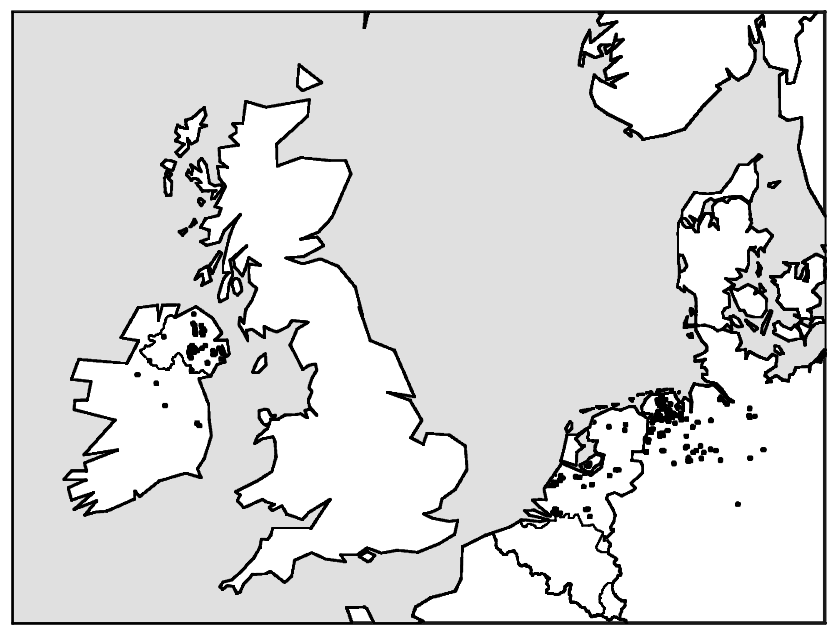

Figure 1 Location of bog-oak finds in Germany, The Netherlands and Ireland. well as all samples from marine and brackish sediments and Dutch bog-oak series investigated after July 2001.

\section{Methods}

\section{Detrending the tree-ring series}

While pines, and to some extent land-grown oaks, have a pronounced growth trend, wherein rings narrow with increasing age, bog-oak tree-ring series are characterized by weak age trends with episodes of increased variability. Given this unusual bog-oak ring pattern, we applied different high-pass filters in order to remove the age trends and to maximize the common long-term variation. Satisfactory results were achieved with the following approach. The series were first logarithmically transformed, then filtered by a dynamically weighted moving average. The length of the moving average varies according to the variance of the ring-width series. On average, the filter width was defined as 140 years (variable Kern-Filter; Riemer, 1994). In this manner, volatile intervals with a large variance, such as abrupt changes of the growth rate, are filtered more intensively than smooth intervals that show little variance. Other (statically weighted) filters would have turned long-term growth changes into more gradual fluctuations. To enhance the long-term growth variations of the resulting index tree-ring chronologies we used a (parabolic) weighted 15-year running mean as a low-pass filter (Riemer, 1994). This filter was also used to remove the high-frequency component from the mean-age chronologies.

\section{Compilation of regional bog-oak chronologies}

We compiled four regional tree-ring chronologies from the dated bog-oak series for (1) northern Germany, (2) The Netherlands, (3) Ireland and (4) a so-called 'continental' chronology, being a combination of all German and Dutch bog-oak series. The chronologies, which together span the interval $6000 \mathrm{BC}$ to $\mathrm{AD} 1000$, were calculated as the arithmetic mean of all the single filtered tree-ring series from each area. A running mean of 15 years was applied to the chronologies to enable visualization of the long-term variability of the average annual growth rates. We also calculated the replication (i.e., the number of trees per calendar year) for chronologies 1 to 3 .

\section{Population dynamics indicated by annual mean age}

The first step was a visual comparison of the temporal distribution of the northern German, Dutch and Irish bog oaks. All the trees were grouped per site against an absolute timescale ( $\mathrm{x}$-axis); every individual tree being represented by a bar that represents its lifespan from germination to death. In case of partly rotten and missing stem segments, an estimation of missing rings to pith and bark was made. A period of five years was taken into account to adjust for the period a tree needs to reach sampling height.

The second step was the calculation of a mean-age chronology for the three regions. The mean-age value for each given year is calculated as the arithmetic mean of the age of all single trees in this specific year. This value combines germination and dying-off phases in a single variable. Besides the calculation of a meanage chronology for Germany, The Netherlands and Ireland, we calculated a so-called continental (combined German-Dutch) mean-age chronology that was subsequently compared to that from Ireland. When interpreting segments of the mean-age 
chronology we focused on two characteristics: intervals with a dominating positive or negative slope and the occurrence of notable maxima and minima, i.e., the heights of positive and negative peaks. The slope of a mean-age chronology in a given period provides information about the relative frequency of trees that germinated and died. The height of maxima in a mean-age chronology is related to the duration of undisturbed phases and the number of dominating old trees that within a given population of trees are able to keep up and survive.

The extremity of minima in a chronology reflects the severity of gap events. Changes of the slope of the smoothed mean-age chronology were calculated using first differences. Maxima and minima were determined visually. With regard to the slope of the mean-age curves, two extremes can be imagined: first, a steady increase at an angle of 45 degrees would imply undisturbed growth conditions and ageing of all trees (with no trees dying); second, an abrupt decrease of a segment of the chronology down to zero, within one year, would indicate that all the trees had died simultaneously. A third theoretical option is where the mean-age chronology is relatively horizontal, implying a 'natural' continuous regeneration, where about the same number of trees germinate and die through time.

To summarize, changes in mean-age chronologies can be interpreted in a meaningful way; in particular, an abrupt decrease in a mean-age chronology will tend to reflect a major gap event following a period of relatively undisturbed growth. In contrast, minor wiggles and changes in slope reflect small-scale population dynamics that occurred on single sites and/or affected only part of the tree population. With this template for interpreting meanage chronologies, we visually compared the first differences of the mean-age chronologies to both the smoothed continental and Irish tree-ring chronologies. Because mean age and detrended ring widths are mutually independent, this helped the objective identification of coincident phases of generation changes and abrupt growth changes.

\section{Results and interpretation}

\section{Temporal distribution of the subfossil oaks}

Figure 2 shows the temporal distribution of the investigated subfossil oak series from northern Germany, The Netherlands and Ireland. The series run from $6069 \mathrm{BC}$ (Germany) to $\mathrm{AD} 1596$ (Ireland). The German and Irish series are continuously replicated throughout most of this period, whereas the smaller collection of Dutch bog oaks shows a gap between 4700 and 3500 BC. The two oldest collections of Dutch bog oaks are not linked to the main

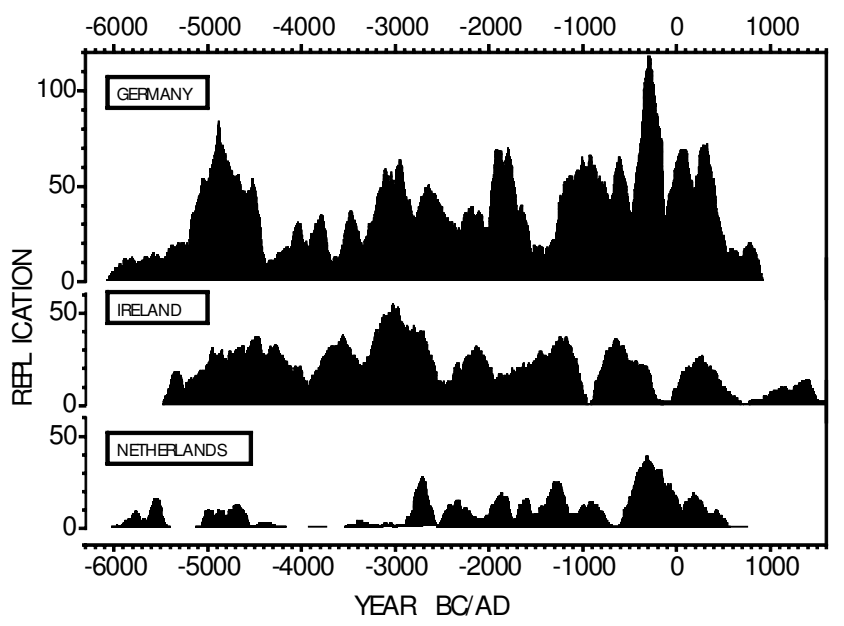

Figure 2 Replication (number of trees through time) of German, Irish and Dutch bog oaks. body of Dutch bog-oak material. These trees, from the fifth and sixth millennia $\mathrm{BC}$, were dated against an earlier version of the German bog-oak chronology (Jansma, 1996). In each of the three regions the replication varies considerably through time (Figure 2). No common interregional variation in the replicated curves can be identified, with the exception of the period between 3300 $\mathrm{BC}$ and $2000 \mathrm{BC}$ where the temporal distribution patterns of German and Irish oaks weakly match.

\section{Characterization of the ring-width pattern}

Figure 3 shows the growth patterns and population dynamics that characterize bog oaks. Two periods are depicted (5400-3600 BC, and 1200 BC-AD 600). Subsets of the German bog-oak series that date within these periods are grouped by site and according to the date of their death.

The ring patterns of all oaks show long-lasting growth depressions (sequences of narrow rings, marked in black) many of which start and end abruptly (Figure 3). They occur synchronously in both young and old trees, which means that there is no age-dependent difference in susceptibility to growth-limiting factors. Most of the bog-oak samples lack at least the outermost sapwood rings. Therefore it was not possible to check if phases of dying-off are preceded by growth depressions. However, some samples that do contain the outermost rings reveal long-lasting growth depressions before dying-off (Figure 3). Growth depressions are in part site-specific, but also occur synchronously across different sites. The regional chronologies clearly express these common phases of suppressed growth (e.g., Figure 8).

\section{Characterization of the population dynamics}

Figures 4 and 5 show the temporal distribution of the German and Dutch as well as the Irish bog oaks from $6200 \mathrm{BC}$ to AD 1700, with the regional mean-age chronologies beneath. Obvious phases of combined germination and dying-off events (GDOs) are marked by dotted lines and are labelled in two digits according to their date (e.g., $\mathrm{BC} 52=5200 \mathrm{BC}$ and $\mathrm{AD} 04=\mathrm{AD} 400$ ).

In terms of general trends in population dynamics, we can distinguish two different patterns of development, most likely reflecting two different types of woodlands. The first type represents woodlands that developed and existed during a period of hundreds, sometimes thousands of years. In these sites we can observe less distinct phases of germination and dying-off (German sites 201 and 307; Figure 4). The second type represents woodlands where the majority of oak trees existed for only a few hundred years, representing essentially one generation of trees. Here, germination and dying-off was much more pronounced (Figure 3 a no.115; Figure 3 b no. 323).

Generation changes (GDOs) in bog oaks are not distinct in terms of clearly defined successive phases of dying-off and germination (Figures 3, 4 and 5). We find no evidence of abrupt 'catastrophic' dying-off events, with many trees dying in the same (single) year. Instead, we observe patterns of accumulated dyingoff events which spanned several years to decades, sometimes coinciding with or followed by phases of regeneration on the same or different sites (Figure 3a, around 5000 BC). Phases of dyingoff often coincided with growth depressions in the surviving trees (Figure 3b, around $700 \mathrm{BC}$ ). The German material shows intervals of striking intersite agreement in terms of germination and dyingoff events (generation change; Figures 3, 4 and 5; Table 1). Most of these generation changes are clearly reflected in the affiliated mean-age chronologies. In general, it can be seen that the mean age of the trees steadily increases when no or only minor population changes occur and the existing trees live on. It decreases when older trees die while younger trees live on and new trees germinate, or when the germination rate exceeds the dying-off of (older) trees. In more general terms, this could be thought of as undisturbed (mean age increasing) and disturbed (mean age 


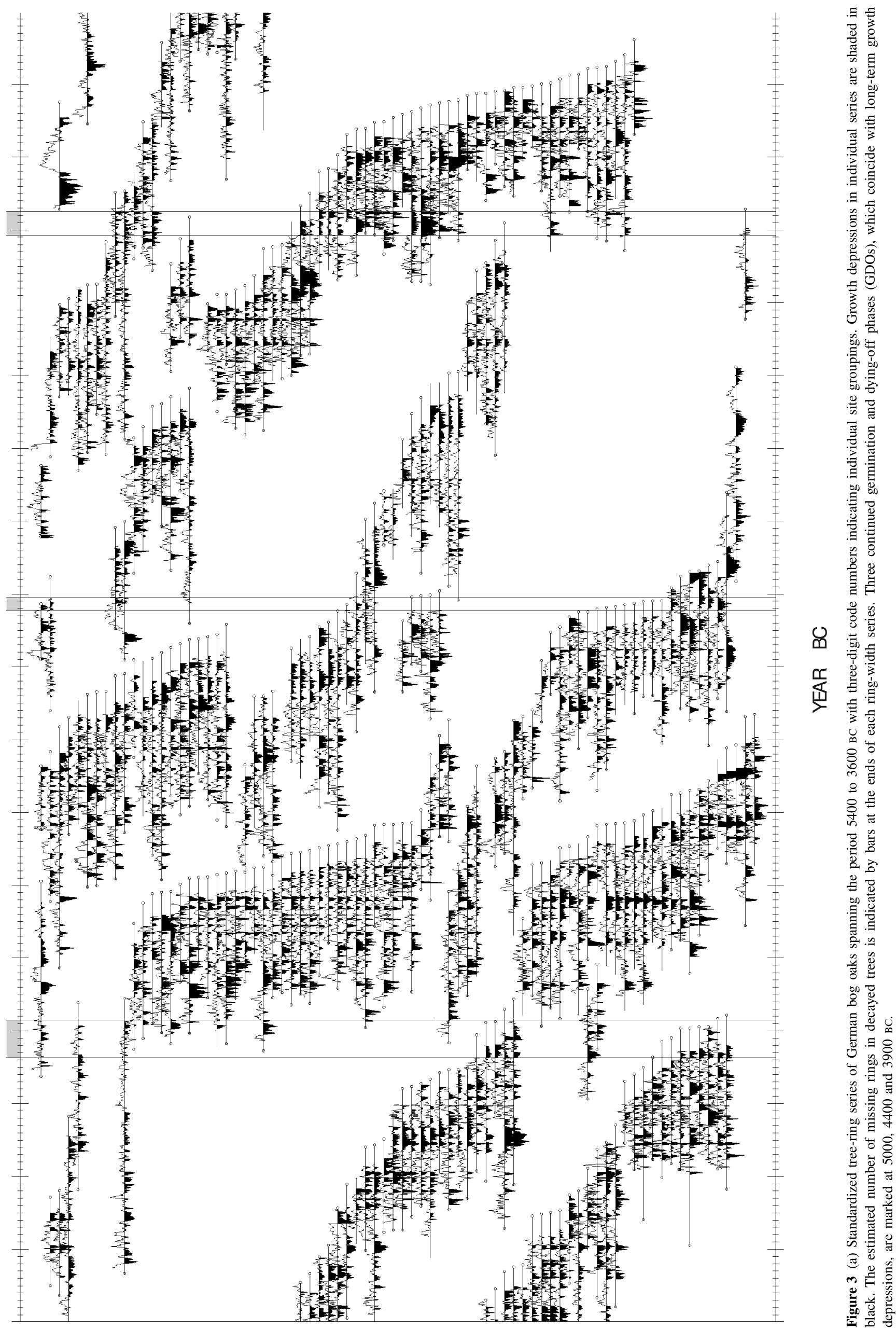




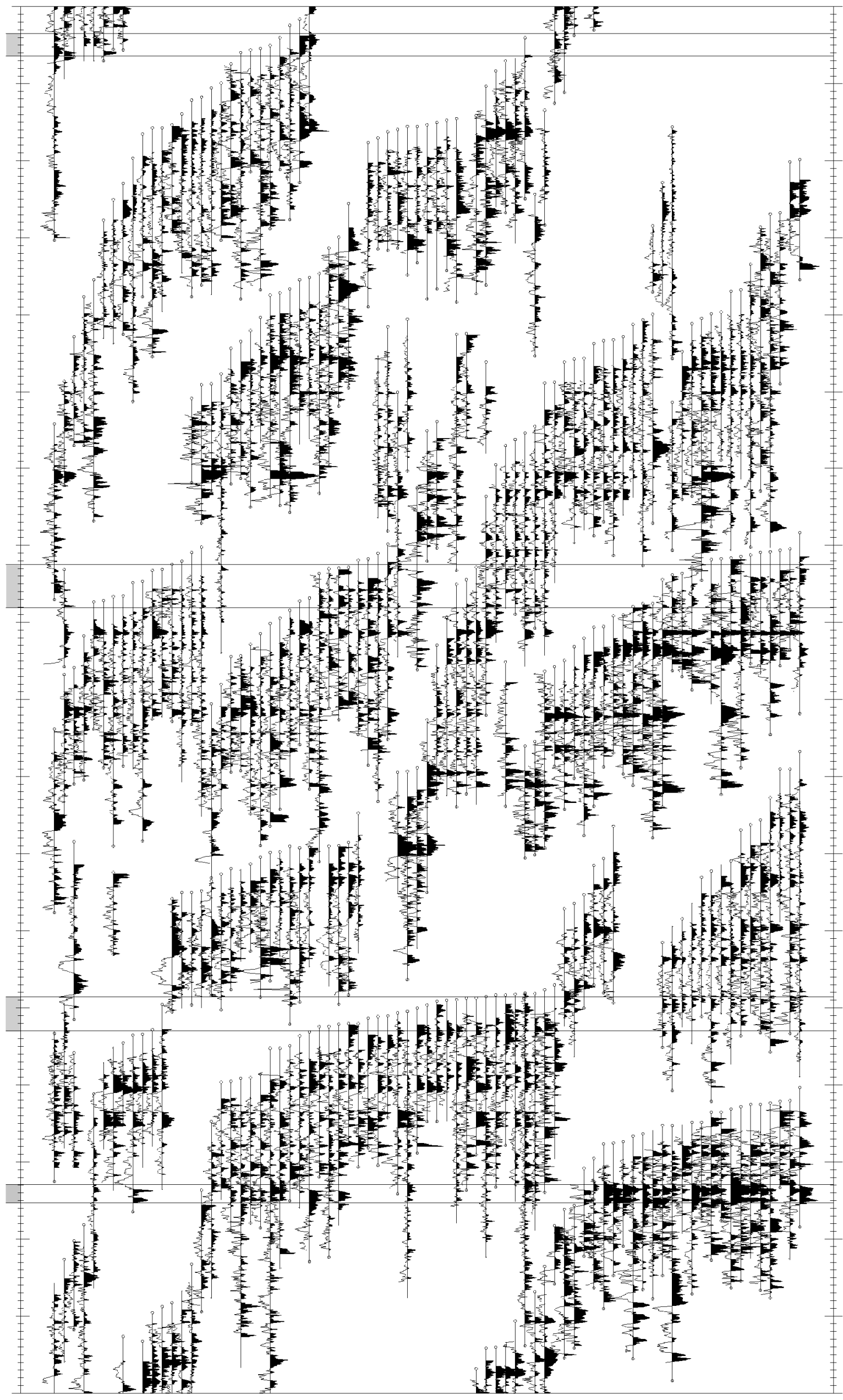




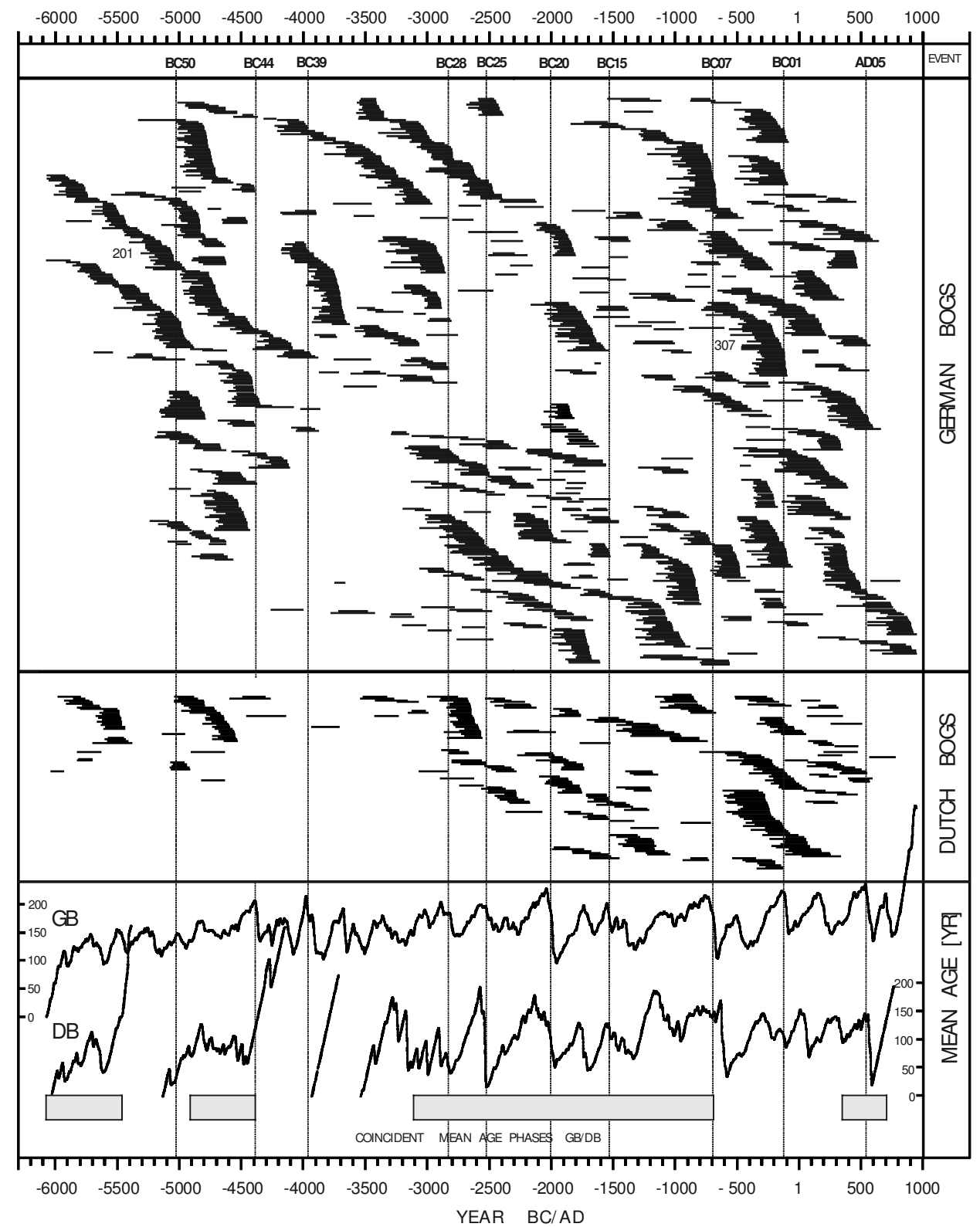

Figure 4 The lifespans of bog oaks from Germany (GB, $n=1561,101$ sites) and The Netherlands (DB, $n=301,43$ sites) clustered according to their site provenance. The lower curves represent the annual mean ages of the trees in the two regions through time. Decreases in the mean age (determined optically) are marked by dotted lines and labelled in two digits according to their date (e.g., BC50 = 5000 BC and AD05 $=$ AD 500). Episodes of notable similarity are shown by grey boxes.

decreasing) populations. Striking changes in population dynamics, reflected by a sudden drop of the mean-age values in both the German and Dutch mean-age chronologies, occurred around 5040, $4350,3970,2820,2550,2000,1550$ and $150 \mathrm{BC}$ and $\mathrm{AD} 540$ (Table 1). In these periods, a lot of older trees suddenly die and at the same time or with some delay - many young trees enter the collections. The steep decrease is pronounced by the preceding relatively long periods (200 to 300 years) of undisturbed tree growth (horizontal or positive slope; e.g., 2820 BC, 720 BC). Looking at the $3970 \mathrm{BC}$ event, it becomes obvious that changes in population dynamics are not necessarily the result of one drastic event, but may occur as the result of successive events.

Most GDOs listed in Table 1 also show up in the Irish bog oaks. However, in Ireland the most striking event took place around 950 $\mathrm{BC}$, which represents a complete generation change and a change to sites without surviving older trees. The German and Dutch mean-age chronologies show a generally good agreement, especially in the well-replicated intervals (Figure 4). Problems occur in weakly replicated intervals, such as the period around
700 BC, where one single oak dominates the run of the Dutch mean-age chronology and dampens its negative slope.

The good agreement between the German and the Dutch treering chronologies (also reflected by good intercorrelation in the high-frequency variations, not shown here) and the mean-age chronologies justified the combination of the German and Dutch bog oaks into a continental subgroup.

\section{Comparisons of the continental and Irish mean-age chronologies}

In Figure 6, we compare the continental mean-age chronology to the Irish mean-age chronology. Despite the great distance between both regions the agreement is remarkable. Between $c .5500$ and $2000 \mathrm{BC}$ there is agreement between the low-frequency variability of the chronologies, and in addition synchronous GDOs occur, for example, around 3970, 2820 and $2000 \mathrm{BC}$. While at first sight the strong drop at $2000 \mathrm{BC}$ seems to be lagged by around 50 years in the Irish mean-age record, closer inspection indicates that the rapidly rising age curve in Ireland shows a break of slope 


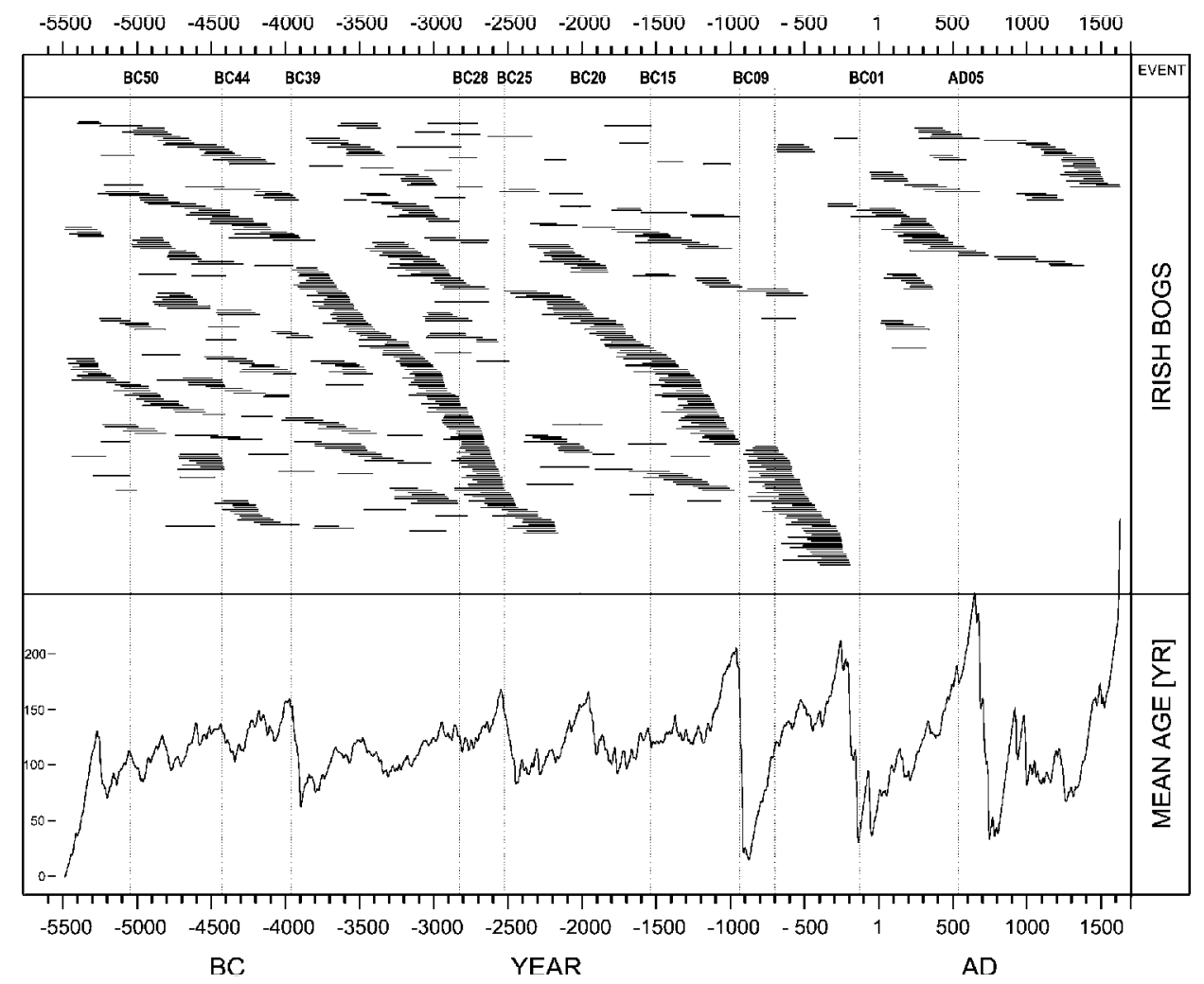

Figure 5 The lifespans of Irish bog oaks (IB, $\mathrm{n}=741,51$ sites) clustered according to their site provenance. The lower curve represents the annual mean age through time. Decreases in the mean age (determined optically) are marked by dotted lines and labelled in two digits according to their date, as in Figure 4.

Table 1 Examples of major germination and/or dying-off events in European bog oaks

\begin{tabular}{|c|c|c|c|c|c|}
\hline \multirow[t]{2}{*}{ Time } & \multicolumn{3}{|c|}{ Kind of event* } & \multicolumn{2}{|c|}{ Simultaneous depression } \\
\hline & Germany & Netherlands & Ireland & Continent & Ireland \\
\hline-5040 & GDO & G & GDO & yes & yes \\
\hline-4350 & GDO & - & GDO & yes & yes \\
\hline-3970 & GDO & G & GDO & yes & no \\
\hline-2820 & GDO & GDO & GDO & no & no \\
\hline-2550 & GDO & GDO & GDO & no & yes \\
\hline-2000 & GDO & GDO & GDO & yes & yes \\
\hline-1550 & GDO & GDO & - & yes & yes \\
\hline-950 & - & - & GDO & yes & yes \\
\hline-720 & GDO & DO & G & yes & yes \\
\hline-150 & GDO & GDO & - & yes & yes \\
\hline+540 & GDO & GDO & GDO & yes & yes \\
\hline
\end{tabular}

$* \mathrm{G}=$ germination, $\mathrm{DO}=$ dying off, $\mathrm{GDO}=$ both.

synchronous with the German record. So, although not precisely in synchronization, even at this point the two records retain a strong similarity.

If we accept that there is good long-distance agreement from c. 5500 to $2000 \mathrm{BC}$ in the low-frequency component of the chronologies, interestingly there is also strong agreement in the highfrequency variability for this time interval. However, after 2000 $\mathrm{BC}$, this situation also changes with the former, generally good, agreement disappearing. Shorter periods of similar population dynamics reappear after $700 \mathrm{BC}$. It is obvious from this comparison that around $2000 \mathrm{BC}$ something happened which caused a shift in growth conditions in either one or both regions, and that this shift led to different and non-synchronous population dynamics.

\section{Comparisons of mean-age chronologies and long-term ring-width variations}

Figure 7 outlines the relationship between the mean age and the long-term tree-ring width variations of the continental bog oaks between 2000 and 1000 BC. First differences, used to detect abrupt changes of the mean-age chronology, show minimal values around 1740, 1680, 1550, 1470, 1400 and 1030 BC. These all coincide with contemporary long-term depressions in the tree-growth chronology. The length of the growth suppression provides a hint to the duration of unfavourable growth conditions. The pronounced slope of the mean-age chronology at these events indicates changes in population dynamics which occurred abruptly and which concerned the 


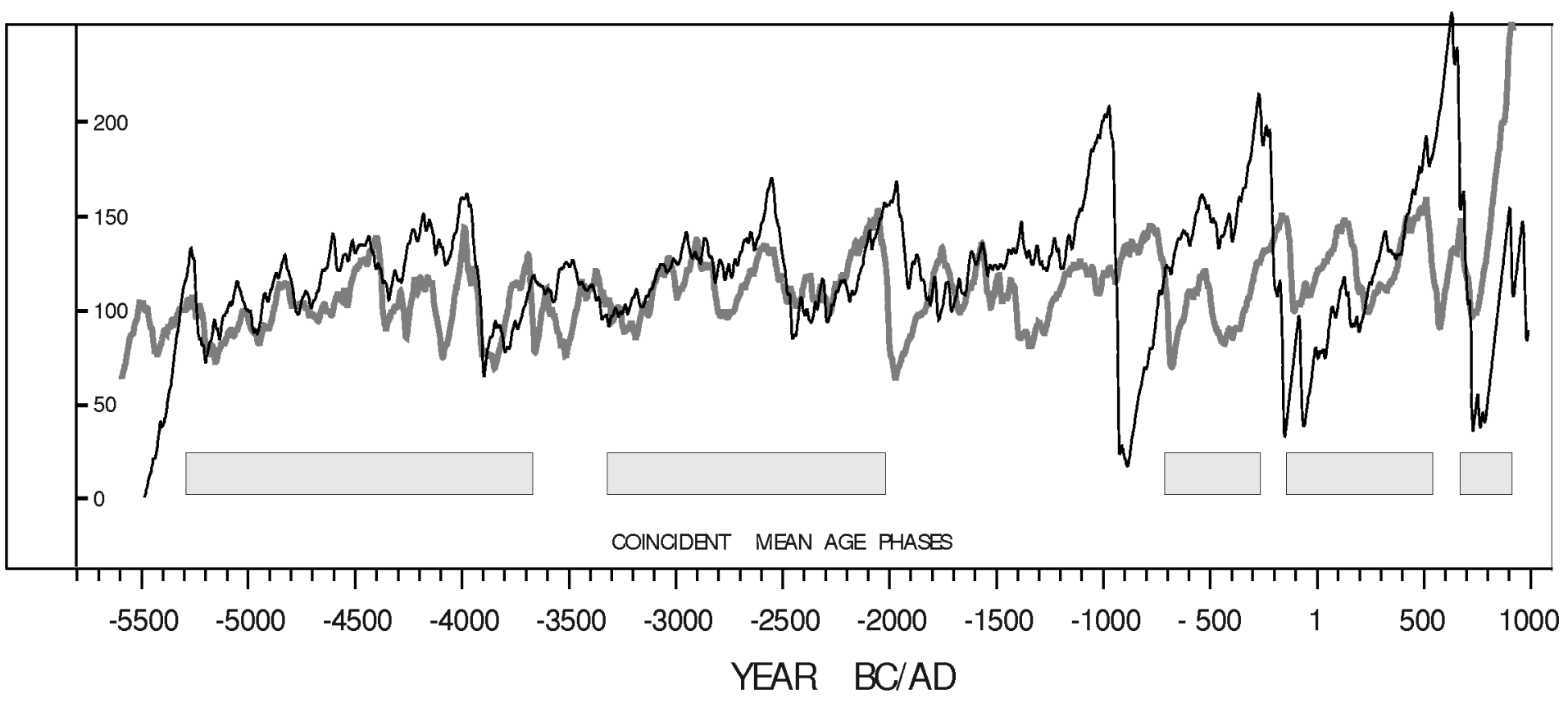

Figure 6 Regional-scale comparison of annual mean-age chronologies between continental (all German and Dutch; grey) and Irish bog oaks (black). Phases of good agreement are shown by grey boxes.

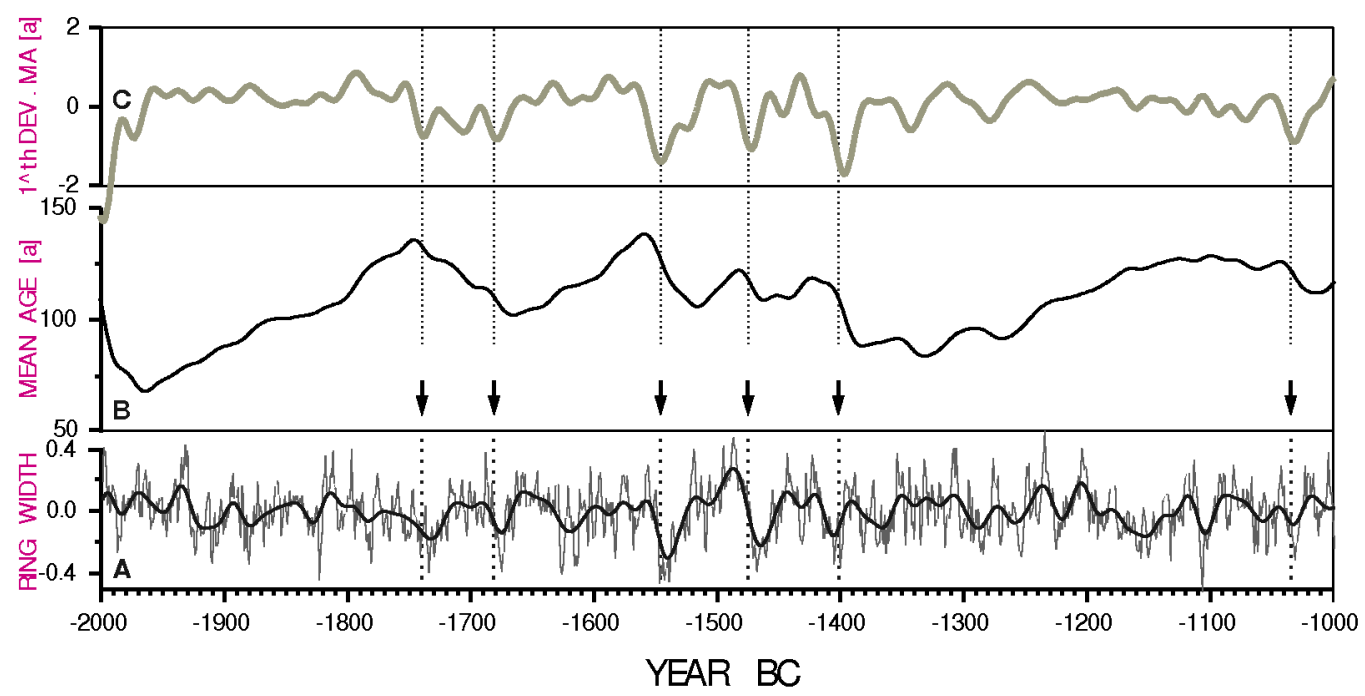

Figure 7 Example period (2000-1000 BC) for the continental (combined German and Dutch material) oaks comparing the smoothed tree-ring chronology (A), the mean-age chronology (B) and the chronology of first differences derived from the mean-age chronology (C), with 15-year running means. Arrows indicate grown depressions in the tree-ring chronology, which coincide with abrupt changes in the slope in the mean-age chronology, expressed by minimum peaks in the chronology of first differences.

majority of the trees. This means that these striking changes, both in ring width and in population dynamics, may have been related to general shifts towards growth-limiting environmental conditions.

We compared the most important tree-ring parameters, i.e., long-term variations in annual tree growth and mean age (first differences), throughout the Holocene for the continental and Irish bog oaks (Figure 8 ). The upper graph in Figure 8 shows the annual tree-ring-width chronologies with periods of good visual agreement marked in grey. In general, the chronologies agree well across relatively long intervals. Exceptions are intervals where the replication is poor, such as around $1000 \mathrm{BC}$ and between 2600 and $2400 \mathrm{BC}$ (see also Figures 2 and 5). A reason for the poor agreement around 1 to $300 \mathrm{BC}$ may be that this period in the Irish bog-oak chronology is replicated by English land-grown trees from Roman sites; no bog oaks could be found in Ireland between c. 230 and $50 \mathrm{BC}$ (Baillie, 1995).
Significantly, in contrast to the breakdown in similarity between the mean-age chronologies after $2000 \mathrm{BC}$ (noted above), no obvious change in agreement can be noticed between the continental and Irish tree-ring chronologies for the period after 2000 BC; on the contrary, there is a good visual tree-ring agreement in the period between 2400 and $400 \mathrm{BC}$.

The two annual growth chronologies and the first-difference series of their mean-age chronologies agree well across large intervals (Figure 8). This means that annual-growth rates and annual mean age, which are statistically independent, in part reflect the same ecological changes. Many of these changes are represented by both the continental and Irish data sets. This agrees with our hypothesis that they must have been the result of a strong common forcing by macroscale environmental factors. This reinforces the idea that mean age is giving a different interpretation of past conditions in comparison with more conventional tree-ring-width chronologies. 


\section{Discussion and conclusion}

The analysis of large dendrochronologica data sets of northwestern European bog oaks in terms of mean age produces clear data about the population dynamics in former mire woodlands. Together with detailed information from the associated ultra-long tree-ring chronologies, they constitute a valuable basis for the reconstruction of large-scale changes of the Holocene hydroregime.

The similarity of both parameters, mean age and tree-ring width, is striking for the whole of the research interval, c. 6000 $\mathrm{BC}$ to $\mathrm{AD} 1000$. Given the scale of the similarity (see, for instance, the interval 5400-2000 BC), it is highly unlikely that it was the result of synchronous human intervention; parallel changes are observed to occur in Germany, The Netherlands and Ireland. Taking into account that the ecological conditions in former mire woodlands were marginal for oak, this similarly must have been the result of a strong forcing by macroscale environmental influences. These influences were most likely expressed as hydrological changes. It is evident that changes of hydrology have a major impact on tree growth and population dynamics in mire woodlands; this holds true for changes towards both drier and wetter conditions. Oaks that grow in mire woodlands have shallow roots and are therefore susceptible to a decreasing groundwater table (Schmid et al., 1995). However, abrupt, long-term changes towards lower groundwater tables are not very likely to occur in natural mire ecosystems; they are more common in woodlands that are influenced by human activity. Besides, a change towards generally drier conditions would have prevented the preservation of dead trees in the peat; whereas we do in fact find their remains today. An increase of the already high groundwater table, on the other hand, induces anoxic conditions in the root zone and results in growth depressions and - if occurring for longer periods - may cause the dying-off of trees (Kozlowski, 1984). This scenario is most likely what happened in (former) mire woodlands. The major arguments that confirm this view are listed below.

The continental (combined German and Dutch) and the Irish mean-age chronologies show a striking similarity throughout long periods in the Holocene. Eleven very clear germination and dyingoff events (GDOs, Table1) are marked as major gap events, i.e., periods of generation change in mire woodlands in northwestern Europe. In most cases, these events coincide with long-term changes in the tree-ring pattern of the European bog oaks. Some of these events have been mentioned as periods of environmental changes that were indicated from other proxy records or observations. One very clear dying-off/germination phase occurred between 4000 and 3900 BC. During this period, the climate in northwestern Europe appears to have been relatively wet, something which first showed up in terms of a chronology construction problem in both areas (Baillie, 1995). In addition, there is a gap event visible in the German riverine material (Spurk et al.,, this issue). Then, until $2600 \mathrm{BC}$, it gradually became drier. This is indicated in Ireland where the greatest abundance of bog oaks occurs in this interval (Figure 2). Between 2600 and 2500 BC it again seems to have become wetter, with one of the periods of poorest replication in the Irish chronology centred on 2500 BC (Baillie et al., 1983; Brown et al., 1986). It is interesting that in Figure 5 there is a long-term overall increase in the Irish meanage curve from 3900 until 2600 BC, also implying a turn to relatively stable and presumably drier conditions.

After 2000 BC there is a lack of agreement between the largescale continental and Irish mean-age chronologies. In this context it is interesting to mention Dalfes et al. (1997) who document widespread indications of major environmental change in the later third millennium BC. Thus it could be that around 2000 BC there was a 'system shift' in global climate and the effects are seen in the breaking-down of an otherwise stable set of long-distance similarities in European oak. However, there is also the possibility that human activity starts to have greater effects on the landscape. As an example of the difficulty of separating human and natural factors, take the very notable drop in the Irish mean-age chronology at 950 вС. Baillie and Brown (1996), looking purely at the Irish evidence, have noted that this drop in the frequency of naturally preserved bog oaks in Ireland coincides with a major building phase involving oak trackways and settlements in bogs; something they argue may have been due to overall drier conditions between c. 1000 and 880 BC. However, reference to Figure 3b and Figure 8 shows that German bog oaks exhibit severe growth depression in the middle of the tenth century BC. This wider context implies an environmental component, which could involve wetter conditions, something that could equally have contributed to the demise of Irish bog oaks at that time.

Indications for another sudden turn towards wetter climatic conditions in the first millennium $\mathrm{BC}$ can be found from dendrochronologically dated wood from continental archaeological excavations. One example involves two distant sites, an iron-age settlement in Biskubin, Poland (Wazny, 1994), constructed around $720 \mathrm{BC}$, which was abandoned most likely because the conditions became too wet, and a bog trackway in northwestern Germany (Schmidt, 1993), which was constructed between 720 and 710 ВC and which was overgrown in a relative short period by raised bog. Here it is the rapid bog growth which implies wetter conditions influencing the human construction activity. Note how the dendrochronological dates make for total separation of this event from the $c .1000$ to $880 \mathrm{BC}$ phase in Ireland; something which might not be so obvious if a radiocarbon chronology were involved.

Another example relates to the $c .150$ BC event indicated in Figures $3 b$ and 4 . Here we find disparate pieces of relevant evidence. First, there is the near disappearance of Irish bog oaks between c. 230 and $50 \mathrm{BC}$, something which should imply bogs becoming wetter. Second, there is a major dying-off phase in the German bog oak material (Delorme et al., 1981; 1983) and a germination phase in the German riverine oak material just at the same time (Delorme and Leuschner, 1983; Spurk et al., this issue). Spurk et al. (this issue) state that such germination phases were generally triggered by wet conditions. However, the construction of major, and very similar, oak roadways in Ireland in 148 BC (Baillie and Brown, 1996) and in Germany c. 180 BC and c. 130 BC (Raftery, 1996) again introduces human-related evidence for interaction with wet areas into the overall environmental equation. Thus it may well be that increasingly wet conditions force people to construct trackways across bogs in order to maintain pre-existing routes.

It is not possible to document every detail of the mean-age chronologies in a single paper, but hopefully the points made above give an indication of the possibilities opened up by having access to large bodies of precisely dated tree-ring data from a wide geographical grid. However, it is worth pointing out one last striking GDO event which shows up very clearly in the German and Dutch records (Figure 4). This event occurred around AD 540, a date which has already been observed as a global tree-ring downturn associated with a severe dust-veil event (Baillie, 1994). Currently there is a debate as to the cause of the global event, with two schools of thought. One suggests a volcanic cause involving a hypothesized supervolcano erupting in AD 535 (Keys, 1999), and the other (Baillie, 1999) suggests that the dust-veil event may have been the result of a close interaction with a comet, or its debris, in the vicinity of AD 540. In the Irish mean-age chronology (Figure 5) the mean age of bog oaks continues to rise until well after $\mathrm{AD} 540$, and it can be seen from the upper chart that this is because few new bog oaks are being recruited, implying that conditions were becoming increasingly unsuitable for regeneration on Irish bogs. 


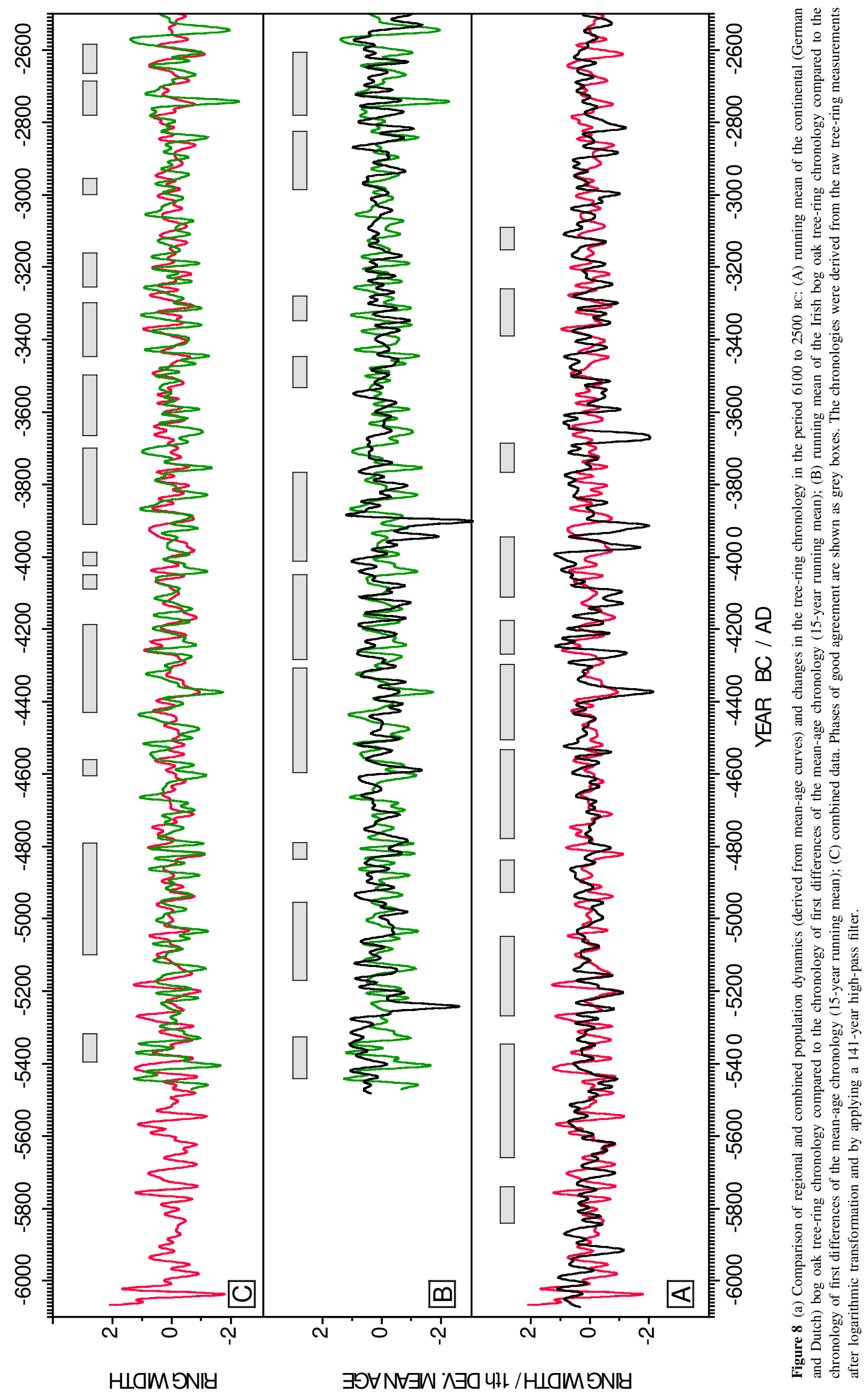




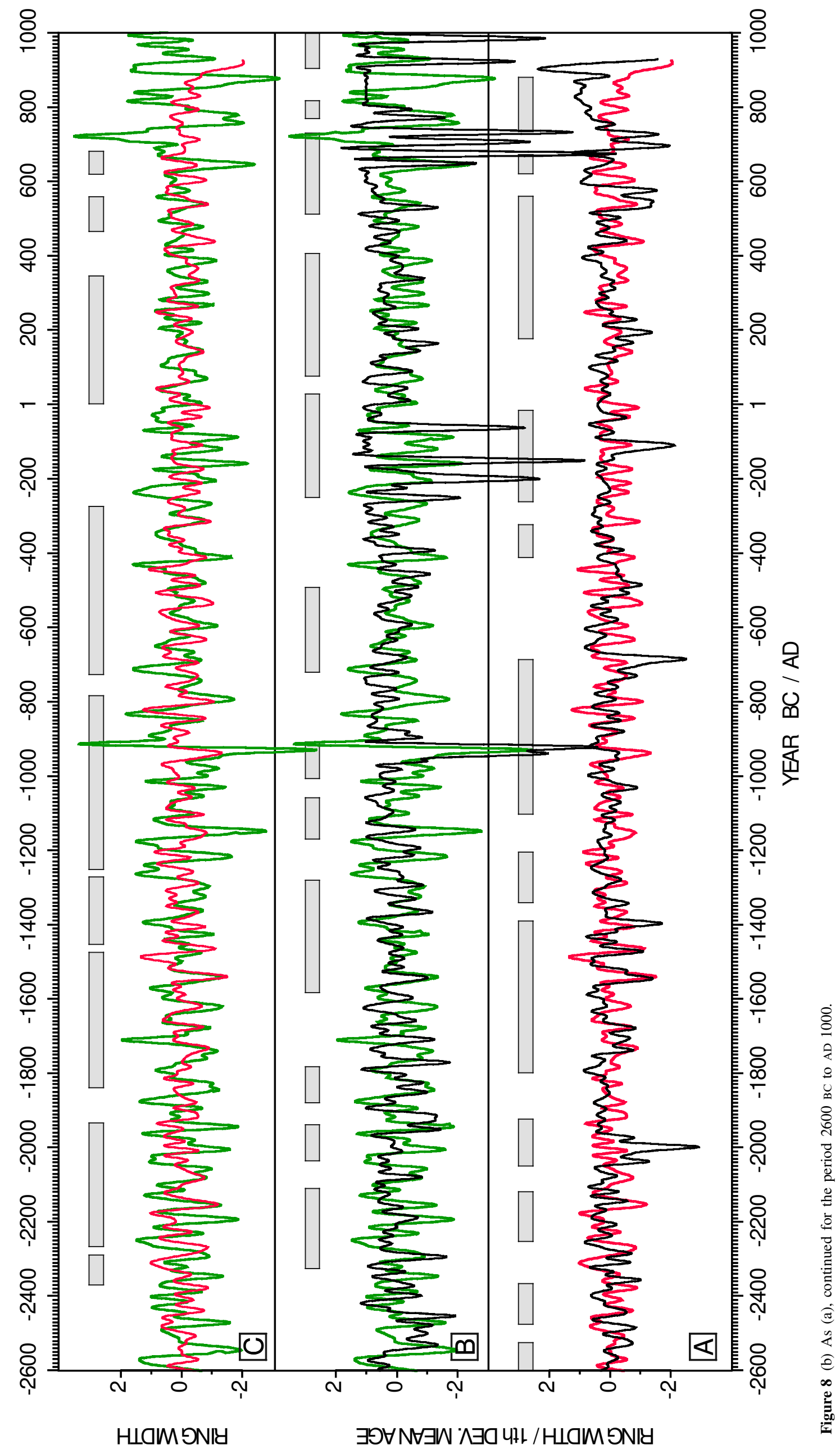


It can be concluded that the mean-age approach has the power to mark major changes in population dynamics and thus climate conditions in a period spanning many thousands of years. However, to get a better understanding of this detailed information more research is needed about (1) the development, structure and ecology of different types of former mire woodlands and (2) the aspects of the preservation of tree remains. First attempts have been made by Delorme etal. (1983), Leuschner et al. (1986; 1987), and by Lageard et al. (1995), who excavated a mire woodland in Cheshire, UK. More results will soon be available from two excavations in Ypenburg and Zwolle, the Netherlands. Oak supporting mire woodlands were very complex ecosystems with many subtypes that occurred due to differences in geographical location, topography, geology, soil characteristics and hydrology. However, all these subtypes can be sensitive indicators for changes in hydrology.

\section{Acknowledgements}

The research was supported by the 'Environment and Climate Programme' under contract ENV4-CT95-0127 and by The Netherlands Organization of Scientific Research (NWO/GW; 25051-072 and NWO/AWL 750.700.04).

\section{References}

Armstrong, W., Brändle, R. and Jackson, M.B. 1994: Mechanisms of flood tolerance in plants. Acta Botanica Neerlandica 43, 307-58.

Baillie, M.G.L. 1994: Dendrochronology raises questions about the nature of the AD 536 dust-veil event. The Holocene 4, 212-17.

— 1995: A slice through time: dendrochronology and precision dating. London: Batsford, $176 \mathrm{pp}$

- 1996: Extreme environmental events and the linking of the tree-ring and ice-core records. In Dean, J.S., Meko, D.M. and Swetnam, T.W., editors, Tree rings, environment, and humanity, Radiocarbon, Department of Geosciences, University of Arizona, Tucson, 703-11.

_ 1999: Exodus to Arthur: catastrophic encounters with comets. London: Batsford, $272 \mathrm{pp}$.

Baillie, M.G.L. and Brown, D.M. 1996: Dendrochronology of Irish bogtrackways. In Raftery, B., editor, Trackway excavations in the Mountdillon Bogs, Co. Longford, Irish Archaeological Wetland Unit, Transactions Vol. 3, Dept. of Archaeology, University College, Dublin, 395-402.

Baillie, M.G.L., Pilcher, J.R. and Pearson, G.W. 1983: Dendrochronology at Belfast as a background to high-precision calibration. Radiocarbon $25,171-78$

Brown, D.M., Munro, M.A.R., Baillie, M.G.L. and Pilcher, J.R. 1986: Dendrochronology - the absolute Irish standard. Radiocarbon 28(2A), $279-83$.

Dalfes, N.H., Kukla, G. and Weiss, H. 1997: Third millennium BC climate change and Old World collapse. Berlin: Springer, 728 pp.

Delorme, A. and Leuschner, H.H. 1983: Dendrochronologische Befun-de zur jüngeren Flussgeschichte von Main, Fulda, Lahn und Oker. Eiszeitalter und Gegenwart 33, 45-57.

Delorme, A., Leuschner, H.H., Höfle, H.-Ch. and Tüxen, J. 1981: Über die Anwendung der Dendrochronologie in der Moorforschung am Beispiel subfossiler Eichenstämme aus niedersächsischen Mooren. Eiszeitalter und Gegenwart 31, 135-58.

Delorme, A., Leuschner, H.H., Tüxen, J. and Höfle, H.-Ch. 1983: Der subatlantische Torfeichenhorizont 'Sieden', erneut belegt im Toten Moor am Steinhuder Meer. TELMA 13, 33-51.

Huber, B., Jazewitsch, W. von, John, A. and Wellenhofer, W. 1949: Jahrringchronologie der Spessarteichen. (Tree-ring chronology of Spessart oak). Forstwissenschaftliches Centralblatt 68, 706-15.

Jansma, E. 1995: RemembeRINGs. The development and application of local and regional tree-ring chronologies of oak for the purposes of archaeological and historical research in the Netherlands. PhD dissertation, University of Amsterdam. Nederlandse Archeologische Rapporten (NAR) 19, $149 \mathrm{pp}$

1996: An 1100-year tree-ring chronology of oak for the Dutch coastal region. In Dean, J.S., Meko, D.M., Swetnam, T.S., editors, Tree-rings, environment and humanity, Proceedings of the International Conference, Tucson, Arizona, 17-21 May, Tucson: Radiocarbon, 769-78.

Keys, D. 1999: Catastrophe: an investigation into the origins of the modern world. London: Century, 368 pp.

Kozlowski, T.T. 1984: Flooding and plant growth. London: Academic Press, 356 pp.

Lageard, J.G.A., Chambers, F.M. and Thomas, P.A. 1995: Recording and reconstruction of wood macrofossils three-dimensions. Journal of Archaeological Science 22, 561-67.

Leuschner, H.H. 1992: Subfossil trees. In Bartholin, T., editor, Tree-rings and environment, Proceedings of the International Dendrochronological Symposium, Ystad, South Sweden, LUNDQUA Report 34, 193-97.

Leuschner, H.H. and Delorme, A. 1986: Dendrochronologische Befunde zu Torfeichen aus dem Kehdinger Moor bei Hammah, Kreis Stade. In Landkreis Stade, editor, Landschaftsentwicklung und Besiedlungsgeschichte im Stader Raum, Stade, 183-89.

Leuschner, H.H., Delorme, A. and Höfle, H.-C. 1987: Dendrochronological study of oak trunks found in bogs in northwest Germany. Proceedings of the International Symposium on Ecological Aspects of Tree Ring Analysis, New York, 298-318.

Leuschner, H.H., Delorme, A., Tüxen, J. and Höfle, H.-C. 1985: Eichenstammlagen in Mooren und Talauen und die Klimaverschlechterung im Subboreal. Flora 177, 283-95.

Leuschner, H.H., Delorme, A., Tüxen, J. and Höfle, H.-C. 1986: Über Eichenwaldhorizonte in küstennahen Mooren Ostfrieslands. TELMA 16, 61-82.

Leuschner, H.H., Spurk, M., Baillie, M. and Jansma, E. 2000: Stand dynamics of prehistoric oak forests derived from dendrochronologically dated subfossil trunks from bogs and riverine sediments in Europe. Geolines 11, 118-121.

Overbeck, F. 1975: Botanisch-geologische Moorkunde: unter besonderer Beruecksichtigung der Moore Nordwestdeutschlands als Quellen zur Vegetations-, Klima- und Siedlungsgeschichte, Neumuenster: Wachholtz, $719 \mathrm{pp}$.

Pilcher, J.R, Baillie, M.G.L., Schmidt, B. and Becker, B.1984: A 7272year tree-ring chronology for western Europe. Nature 312, 150-52.

Raftery, B. 1996: Trackway excavations in the Mountdillon Bogs, Co. Longford. Irish Archaeological Wetland Unit, Transactions Vol. 3. Department of Archaeology, University College, Dublin, 223-26.

Riemer, T. 1994: Ueber die Varianz von Jahrringbreiten. Statistische Methoden fuer die Auswertung der jaehrlichen Dickenzuwaechse von Baeumen unter sich aendernden Lebensbedingungen (Variance of treering widths. Statistical methods for evaluation of the annual increment of trees under changing living conditions). $\mathrm{PhD}$ dissertation, Universitaet Goettingen. Berichte des Forschundszentrums Waldekosysteme, Reihe A $121,375 \mathrm{pp}$

Schmid, J., Bogenrieder, A. and Schweingruber, F.H. 1995: Verjuengung und Wachstum von Moorkiefern (Pinus rotundata Link) und Fichten (Picea abies (L.) Karst.) in Mooren des suedoestlichen Schwarzwaldes (Sueddeutschland) (Regeneration and growth of bog pine (Pinus rotundata Link) and spruce (Picea abies (L.) Karst.) in bogs of the southeastern Black Forest (southern Germany). Mitteilungen der Eidgenoessischen Forschunganstalt fuer Wald, Schnee und Landschaft 70(2), 174-223.

Schmidt, B. 1993: Hölzerne Moorwege als Untersuchungsobjekte für die Dendrochronologie. In Fansa, F., editor, Moorarchäologie in NordwestEuropa, Sonderdruck der Oldenburgischen Landschaft, Isensee Oldenburg, 147-60.

Spurk, M., Friedrich, M., Hofmann, J., Remmele, S., Frenzel, B., Leuschner, H.H. and Kromer, B. 1998: Revisions and extensions of the Hohenheim oak and pine chronologies - new evidence about the timing of the younger Dryas/Preboreal transition. Radiocarbon 40(3), 1-10.

Succow, M. and Joosten, H. 2001: Landschaftsökologische Moorkunde. Stuttgart: Schweizerbart'sche Verlagsbuchhandlung, 622 pp.

Wazny, T. 1994: Dendrochronology of Biskupin - absolute dating of the early Iron Age settlement. Bulletin of the Polish Academy of Sciences, Biological Sciences 42(3), 283-89. 